\title{
Measuring reaction time with millisecond accuracy using the TRS- 80 microcomputer
}

\author{
RICHARD A. OWINGS and CLIFFORD H. FIEDLER \\ George Peabody College, Nashville, Tennessee 37203
}

\begin{abstract}
A machine language subroutine is proposed for measuring reaction time with millisecond accuracy using the TRS- 80 microcomputer. This timer is accurate to $1 \mathrm{msec}$ in the first $30,000 \mathrm{msec}$ and to $5 \mathrm{msec}$ in the first $65,000 \mathrm{msec}(1$ part in 10,000$)$.
\end{abstract}

The TRS-80 microcomputer is likely to become commonplace in information processing research because it is inexpensive, has wide marketing and servicing facilities, is portable, and does not require sophisticated programming (Durrett, 1978; Perera, 1978; Sidowski, 1978).

The TRS- 80 can measure reaction time by means of an incrementing loop. For instance, this BASIC Level 2 loop,

$\begin{array}{ll}100 & \mathrm{~K}=0 \\ 110 & \mathrm{~K}=\mathrm{K}+1 \\ 120 & \mathrm{~A} \$=\mathrm{INKEY} \$ \\ 130 & \mathrm{IF} \text { A } \$=" \text { " } \mathrm{THEN} \mathrm{GOTO} 110 \\ 140 & \text { PRINT "DELAY= ", K, "LOOPS" }\end{array}$

can be used to measure time for several thousand years with $12.5-\mathrm{msec}$ resolution. The program cycles through Lines 110,120 , and 130, incrementing the counter, $\mathrm{K}$, once with each cycle, until the subject responds by hitting a key. Control exits the loop; $\mathrm{K}$ contains the count of loops completed. Because the loop requires $12.5 \mathrm{msec}$ to complete, reaction time in milliseconds can be calculated by multiplying 12.5 by variable $\mathrm{K}$. This is not the fastest possible loop that can be written in BASIC, but simple instructions in BASIC function in the 3- to $10-\mathrm{msec}$ range, and it takes several instructions to execute a loop that will test for an exit condition. The result is loop times in the 10 - to $25 \mathrm{msec}$ range.

A 12.5 -msec timing loop does not provide adequate resolution for all purposes. Sternberg (1975) bases theoretical arguments on reaction time differences of $35 \mathrm{msec}$. Posner's name/physical match contrast yields a difference of about $70 \mathrm{msec}$ (Posner \& Rogers, 1978). Semantic marking appears as a 100-msec difference in reaction time (Chase, 1978). All of these effects are detectable using a $12.5-\mathrm{msec}$ loop; however, only

Reprints are available from the authors at P. O. Box 154, George Peabody College, Nashville, Tennessee 37203. A listing of the assembly language source code is available, as is a wiring diagram for linking the output ports of the TRS-80 to an external clock in order to verify the accuracy of measurement or to control external equipment. The authors thank Judy A. Hanna for her assistance in preparing this manuscript. imprecise parameter estimates can be made. Other effects may be indetectable using a 12.5 -msec loop. For instance, Cavanaugh (1972) bases theoretical assertions on differences among scan rates for various types of materials. Words are scanned at a rate of $33 \mathrm{msec} / \mathrm{item}$; colors, $38 \mathrm{msec}$; letters, $40 \mathrm{msec}$; and forms, $68 \mathrm{msec}$. Differences among these scan rates would not be detectable using a 12.5-msec loop. Radio Shack's expansion interface, with its real-time clock, provides only $25-\mathrm{msec}$ resolution, precluding its usefulness in highresolution timing measurements.

The machine language routine listed in Figure 1 is recommended for measuring reaction times because it provides millisecond accuracy. The user must perform three tasks. (1) Following power-up or reset, the machine asks, "MEMORY SIZE?" The user responds "32000" or according to the configuration table, Figure 2 , in order to protect core memory from BASIC, in which the machine code will be safe to operate. (2) The timer is stored in the protected memory areas as shown in Figure 1, Lines 1-16. These statements may appear at any line number, providing that they are executed before the timer is called. (3) The timer is called as needed within a main program, as illustrated in Figure 1, Lines 100-190. Line 100 is the last line of the user's stimulus generator. Line 110 starts the timer. When the subject responds, the timer stops, and control returns to the main program at Line 120 . Lines 130 and 140 retrieve the count of cycles completed. Line 150 combines the most significant byte and the least significant byte into the decimal equivalent of a 16-bit binary loop count. A correction factor of .9992 is applied because the crystal-controlled loop counter is not quite evenly divisible into millisecond increments. The offset of .6 is added so that rounding occurs when the integer value is taken. The variable RT contains the subject's reaction time. RT may be tested or stored by the user's BASIC program. Variable $\mathrm{N}$ contains a number representing the subject's response, which can be tested or stored or used to generate the string variable RESP\$, as shown. "\%" is the type declaration character for an integer variable, defined as a 16-bit signed binary number with a range of $+32,767$ to $-32,768$. VARPTR is a function that finds the location in core memory 
(A)

\author{
PROTECT MEMORY \\ TURN ON OR RESET MACHINE \\ TRS=80 ASKS, "MEMORY SIZE?" \\ USER REPLIES, "32000" \\ OR AS PER CONFIGURATION TABLE
}

(B)

STORE TIMER

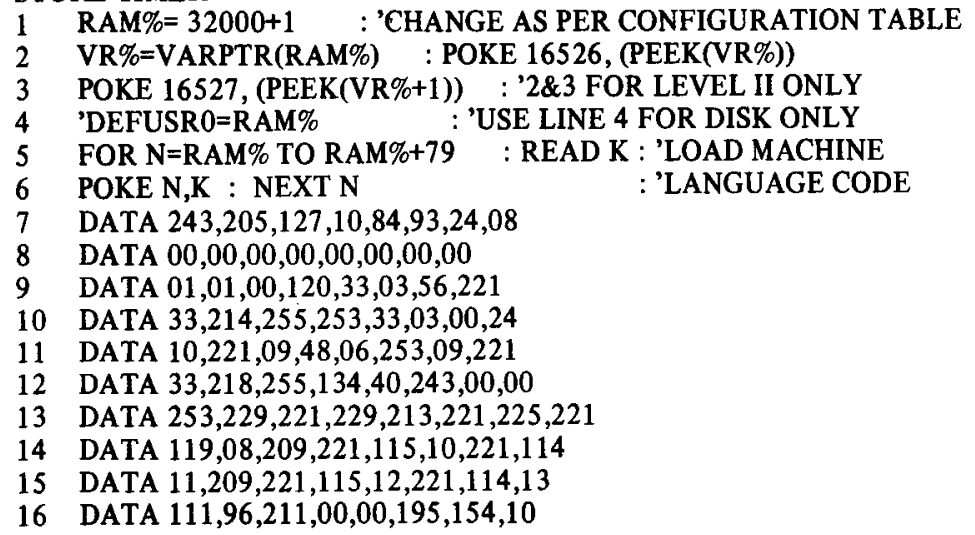

(C)
USE TIMER
100 PRINT @ 540, “GO”
$110 \mathrm{~N}=\mathrm{USR}(\mathrm{RAM} \%)$
110 'N=USR0(RAM\%)
120 CLS
130 LSB=PEEK $($ RAM $\%+12)$
$140 \mathrm{MSB}=\mathrm{PEEK}(\mathrm{RAM} \%+13)$
150 RT=INT(.9992*(((MSB*256)+LSB)+.6)) : 'TIME
160 PRINT "REACTION TIME=", RT " MILLISECONDS",
170 IF N=16 THEN RESP\$="YES" : 'SUBJECT HIT D-KEY
180 IF N=8 THEN RESP\$="NO" : :SUBJECT HIT K-KEY
190 PRINT RESP\$ : 'RETURN :'TO CALLING PROGRAM

Figure 1. Machine language routine. Note that the sixth entry in Statement 9 is "03." This number may be altered to cause particular sets of keys to be scanned.

that BASIC uses to store the value of the variable of interest.

As listed in Figure 1, the program will score a response on the " $D$ " key as "yes" and a response on the " $\mathrm{K}$ " key as "no." This is not immutable. Any key, or an external switch, may be designated a response key. However, the sixth entry in Line 9 of Figure 1, "03," must be altered. Figure 3 provides the necessary information. For instance, to scan Keys 1 and 8, replace " 03 " with " 48 " (the sum of the two row designators). If the " 1 " key is hit, $\mathrm{N}$ will be 2 ; if the " 8 " key is hit, $\mathrm{N}$ will be 1 . The " 1 " and " 9 " keys are indiscriminable using this procedure, as both return $\mathrm{N}=2$. Similarly,

\begin{tabular}{cccc}
\hline \multicolumn{3}{c}{ CONFIGURATION TABLE } \\
SYSTEM & & MEMORY SIZE? & \multicolumn{1}{c}{ RAM\%= } \\
4K & RAM= & 20399 & 20400 \\
16K & RAM= & 32680 & 32681 \\
32K & RAM= & 49070 & -16465 \\
48K & RAM= & 65450 & -85 \\
\hline
\end{tabular}

Figure 2. Configuration table. the "0" and "8" keys both return $N=1$. Note that the program in Figure 1 scores the "L" key (as well as the " $D$ " key) as "yes" and the " $\mathrm{C}$ " key (as well as the "K" key) as "no."

The timer recycles at $65,536 \mathrm{msec}$. Hence, outcomes are ambiguous for reaction times in excess of $1 \mathrm{~min}$. The timer loses $1 \mathrm{msec}$ in the first $30,000 \mathrm{msec}$ and $5 \mathrm{msec}$ in the first $60,000 \mathrm{msec}$. This represents the best straight-line correction through a function that varies exponentially in a stepwise fashion. Verification was performed using a Systron-Donner 214 frequency counter with a crystal time base accurate to 10 parts/ million. The timer was started immediately following stimulus presentation using the BASIC command OUT $(0,1)$ and was stopped immediately after response using the machine language equivalent of the OUT $(0,0)$ command. The second command remains in the program, so the user may verify the accuracy of the timer by inserting OUT $(0,1)$ at Line 100 and decoding the signals on the TRS- 80 interface connector. Data bus Bit 0 of Port 0 is thus latched and used to gate an external timing device. 


\begin{tabular}{lccccccccc}
\hline & & \multicolumn{1}{c}{ COLUMN } & DESIGNATOR & & \\
& & 1 & 2 & 4 & 8 & 16 & 32 & 64 & 128 \\
& 01 & @ & A & B & C & D & E & F & G \\
ROW & 02 & H & I & J & K & L & M & N & O \\
DESIG & 04 & P & Q & R & S & T & U & V & W \\
NATOR & 16 & 0 & Y & Z & EXT & EXT & EXT & EXT & EXT \\
& 32 & 8 & 9 & 2 & 3 & 4 & 5 & 6 & 7 \\
& & & & & & & - & & $/$ \\
\hline
\end{tabular}

Figure 3. Column and row designations. The row designator, when entered as the sixth element in Line 9 of Figure 1, will cause the set of keys in that row to be scanned. The column designator of the particular key hit will be returned as " $N$ " in Line 110 of Figure 1. Two or more rows can be scanned by summing their row designators. An external switch can be arranged to register in one of the "EXT" locations.

Submillisecond accuracy may be achieved using this program. While timing, the IX counter, which is built into the machine hardware, increments from 65,498 to 65,536 , increments the IY counter, and resets to 65,498 . The IX counter may be indirectly addressed by $\mathrm{LSB}=\mathrm{PEEK}(\mathrm{RAM} \%+10)$ and $\mathrm{MSB}=\mathrm{PEEK}$ $(\mathrm{RAM} \%+11)$. Then $\mathrm{M}=((\mathrm{MSB}+256+\mathrm{LSB})-65498) / 38)$ will give the remainder, based on how far the IX counter advanced from 65,498 to 65,536 . This is roughly 26.6 msec resolution.

An assembly language version of the program described herein can be obtained from the authors. The assembly language source listing is easily transportable to machines other than the TRS- 80 .

\section{REFERENCES}

Cavanaugh, J. P. Relation between the immediate memory span and the memory search rate. Psychological Review, 1972, 79, 525-530.

Chase, W. G. Elementary information processes. In W. K. Estes (Ed.), Handbook of learning and cognitive processes: Human information processing (Vol. 5). Hillsdale, N.J: Erlbaum, 1978.

DURRETT, H. J. Inexpensive microcomputer systems for research and instruction: A dream or reality? Behavior Research Methods \& Instrumentation, 1978, 10, 345-351.

Perera, T. B. A versatile microcomputer-based multiple-field tachistoscope. Behavior Research Methods \& Instrumentation, $1978,10,546-547$.

Posner, M. I., \& Rogers, M. G. K. Chronometric analysis of abstraction and recognition. In W. K. Estes (Ed.), Handbook of learning and cognitive processes: Human information processing (Vol. 5). Hillsdale, N.J: Erlbaum, 1978.

Sidowski, J. B. Microcomputers in psychology. Behavior Research Methods \& Instrumentation, 1978, 10, 463-467.

Stennberg, S. Memory scanning. New findings and current controversies. Quarterly Journal of Experimental Psychology, $1975,27,1-32$.

(Received for publication May 2, 1979; revision accepted October $17,1979$. 